\section{International Scientific Journal Theoretical \& Applied Science}

p-ISSN: 2308-4944 (print) e-ISSN: 2409-0085 (online)

Year: $2017 \quad$ Issue: 02 Volume: 46

Published: 10.02.2017 $\quad$ http://T-Science.org
Denis Chemezov

Master of Engineering and Technology, Corresponding Member of International Academy of Theoretical and Applied Sciences, Lecturer of Vladimir Industrial College, Russian Federation chemezov-da@yandex.ru

Oleg Gorbatenko Master of Industrial Training, Vladimir Industrial College, Russian Federation 365573@mail.ru

\title{
THE ACTUAL VALUES OF SOME PARAMETERS OF THE INTERNAL COMBUSTION ENGINE DURING THE VARIOUS MODES OF VEHICLE OPERATION
}

Abstract: The article are presented the results of the computer measurement of the dynamics the change of values of the parameters of the internal combustion engine by means of the automotive diagnostics unit AMD-4AK.

Key words: the diagnostics, a vehicle, frequency of rotation of the crankshaft, ECU, ICE.

Language: Russian

Citation: Chemezov D, Gorbatenko O (2017) THE ACTUAL VALUES OF SOME PARAMETERS OF THE INTERNAL COMBUSTION ENGINE DURING THE VARIOUS MODES OF VEHICLE OPERATION. ISJ Theoretical \& Applied Science, 02 (46): 1-4.
Soi: http://s-o-i.org/1.1/TAS-02-46-1
Doi: crossef https://dx.doi.org/10.15863/TAS.2017.02.46.1

\section{ФАКТИЧЕСКИЕ ЗНАЧЕНИЯ НЕКОТОРЫХ ПАРАМЕТРОВ ДВИГАТЕЛЯ ВНУТРЕННЕГО СГОРАНИЯ ПРИ РАЗЛИЧНЫХ РЕЖИМАХ ЭКСПЛУАТАЦИИ АВТОМОБИЛЯ}

Аннотация: В статье представлены результаты компьютерного измерения динамики изменения величин параметров двигателя внутреннего сгорания посредством блока автомобильной диагностики АМД- 4 АК.

Ключевые слова: диагностика, автомобиль, частота вращчения коленчатого вала, ЭБУ, ДВС.

\section{Введение}

На скорость износа поверхностей деталей влияет характер эксплуатации автомобиля. Наибольшему износу подвергаются детали двигателя внутреннего сгорания (ДВС) воспринимающие значительные механические и температурные нагрузки. Изменения в работе ДВС определяются экспериментально при выполнении компьютерной диагностики. Суть компьютерной диагностики заключается в диагностике электронного блока управления (ЭБУ) автомобиля [1].

Современные диагностические комплексы позволяют осуществлять измерение параметров систем, агрегатов и механизмов автомобиля и сравнивать фактические значения с предельно допустимыми. Своевременная диагностика автомобиля выявляет отклонения параметров за считанные минуты для последующего принятия комплексных мер по их устранению.

На примере автомобиля российского производства приводятся порядок измерения параметров работы ДВС и анализ полученных результатов специальным прибором для проведения компьютерной диагностики (изготовитель - НПП «Новые Технологические Системы», Россия).

\section{Материалы и методы исследования}

Диагностике подвергался легковой автомобиль LADA 219110 GRANTA 2014 года выпуска [2]. Контроль работы бензинового 8клапанного ДВС мощностью 64 кВт (87 л. с.) выполнялся посредством ЭБУ ДВС автомобиля, блока автомобильной диагностики (БАД) АМД4АК [3] и специальной компьютерной диагностической программы МТ10 (версия 4.1.320) [4]. Схема подключения БАД АМД-4АК для выполнения измерений и интерфейс программы МТ10 представлены на рис. 1.

Соединение БАД с ЭБУ двигателя осуществлялось кабелем-адаптером АM4-Д42OBD2 [5; 6]. БАД представляет собой блок с разъемами для подключения кабелей и датчиков на передней панели и разъемами для подключения питания и интерфейсного кабеля на 
боковой стороне. С помощью БАД АМД-4АК возможна диагностика системы зажигания (состояние свечей и свечных проводов, неисправности катушки зажигания, проверка коммутатора и датчика Холла, характеристика работы центробежного регулятора, определение углов опережения зажигания [7]), системы топливоподачи (проверка топливных форсунок, исполнительных механизмов и выхлопных газов), системы газораспределения (компрессия в динамике, оценка установки ремня ГРМ и контроль работы клапанов), системы питания и зарядки.

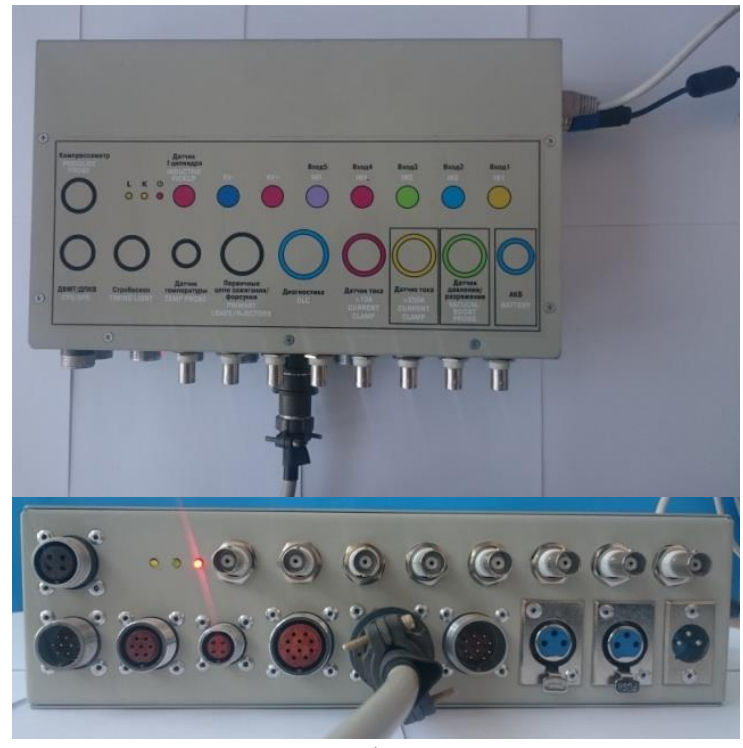

a)

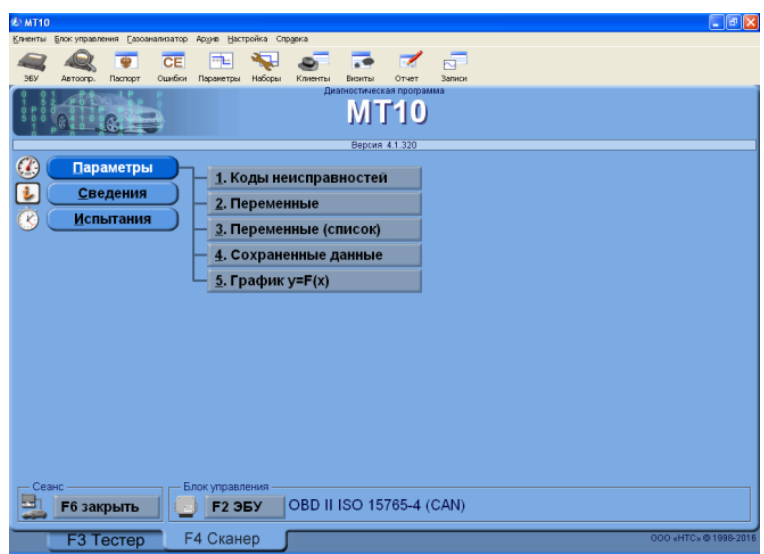

б)

Рисунок 1 - Аппаратное и программное обеспечение процесса диагностики автомобиля: а - схема подключения БАД АМД-4АК для выполнения измерений; б - интерфейс программы МТ10.

В программе МТ10 предусмотрена диагностика подсистем автомобилей отечественного и зарубежного производства в режиме «Сканер» и диагностика ДВС в режиме «Мотор-Тестер». В режиме «Сканер» возможна диагностика более 388 типов ЭБУ с поддержкой интерфейсов ISO9141-2 (K-L-line), J1850 (VPW, PWM), CAN: ISO11898, ISO11519, J2411 и показом параметров в виде графиков. В режиме «Мотор-Тестер» выполняются: оценка относительной компрессии в цилиндрах, измерение давления в цилиндрах, анализ работы генератора и аккумулятора, измерение напряжений, измерение углов опережения зажигания (УОЗ), работа с многоканальным осциллографом с возможностью записи сигналов, измерение температуры ДВС. Измерение производилось в режиме «Сканер».

Испытания выполнялись на двух режимах работы автомобиля: холостой ход (при частоте вращения коленчатого вала ДВС 800 - 850 об/мин) и рабочий режим (при частоте вращения коленчатого вала ДВС 850 - 3000 об/мин). Время измерения на каждом из режимов составило $10 \mathrm{c.}$

По функции $y=F(x)$ выполнялся расчет значений УОЗ для первого цилиндра (градус поворота коленчатого вала), датчика положения дроссельной заслонки (\%) [8], расхода воздуха, измеренного по датчику массового расхода воздуха (кг/ч) и температуры воздуха во впускном коллекторе $\left({ }^{\circ} \mathrm{C}\right)$ от частоты вращения коленчатого вала.

\section{Результаты и их обсуждение}

Значения всех параметров были экспортированы в программу Microsoft Excel.

Обработка результатов измерения представлена в виде графиков зависимостей на рис. 2.

УОЗ для первого цилиндра составляет 6 градусов ПКВ на первых секундах работы автомобиля в режиме холостого хода. На последующих секундах этого режима УО3 изменяется в диапазоне от 7 до 28 градусов ПКВ. При достижении частоты вращения коленчатого вала 2100 об/мин УОЗ составляет 31 градус ПКВ. Величина УОЗ не изменяется при уменьшении частоты вращения коленчатого вала до 1500 об/мин на рабочем режиме. Отрицательные значения УОЗ означают, что поджиг смеси осуществляется при достижении поршня верхней мертвой точки.

На холостом ходу степень открытия дроссельной заслонки составляет $3.5-4.3 \%$. Мощностной режим работы ДВС не достигается, так как при увеличении частоты вращения коленчатого вала до 3000 об/мин степень открытия дроссельной заслонки не более $15 \%$. 


\begin{tabular}{l|lr|ll|ll} 
& ISRA (India) & $=\mathbf{1 . 3 4 4}$ & SIS (USA) & $=\mathbf{0 . 9 1 2}$ & ICV (Poland) & $\mathbf{= 6 . 6 3 0}$ \\
Impact Factor: & ISI (Dubai, UAE) $=\mathbf{0 . 8 2 9}$ & PUHL (Russia) $=\mathbf{0 . 2 3 4}$ & PIF (India) & $=\mathbf{1 . 9 4 0}$ \\
& GIF (Australia) & $=\mathbf{0 . 5 6 4}$ & ESJI (KZ) & $=\mathbf{1 . 0 4 2}$ & IBI (India) & $=\mathbf{4 . 2 6 0}$
\end{tabular}

Датчик положения работает исправно. Дроссельная заслонка перемещается в исходное положение при возвращении в режим холостого хода.

Количество воздуха, поступающее за час в цилиндры ДВС автомобиля, увеличивается в 2 раза при переходе с холостого хода на рабочий режим. Более точные результаты измерения массового расхода воздуха могут быть получены при дополнительных замерах свойств газа (влажность, содержание кислорода и т. д.).

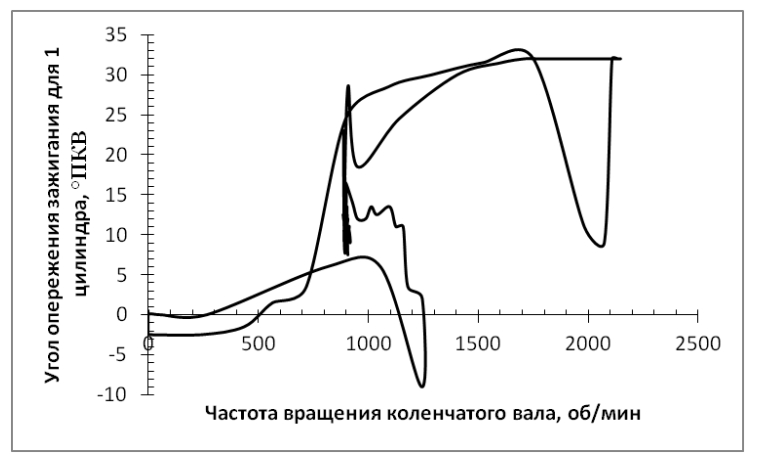

a)

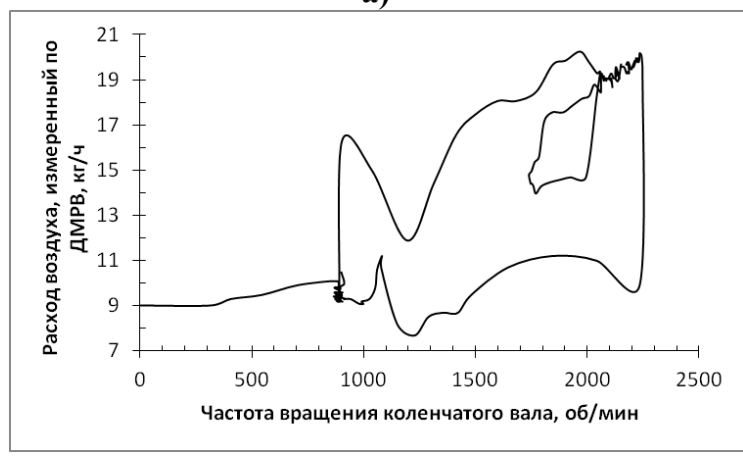

B)
Температура во впускном коллекторе не изменялась в течение 13 с эксплуатации автомобиля (на холостом и частично рабочем режиме) и составляла $21{ }^{\circ} \mathrm{C}$. С уменьшением частоты вращения коленчатого вала с 2400 об/мин до 850 - 900 об/мин за 7 с температура увеличивается на $3{ }^{\circ} \mathrm{C}$. Изменения температуры воздуха во впускном коллекторе от частоты вращения коленчатого вала характеризуются расчетными линейными зависимостями. Температура воздуха в помещении, где выполнялись измерения, была равна $+15^{\circ} \mathrm{C}$.

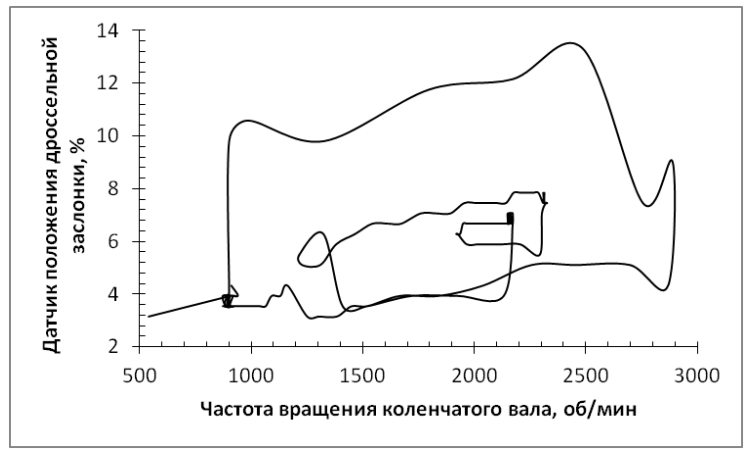

б)

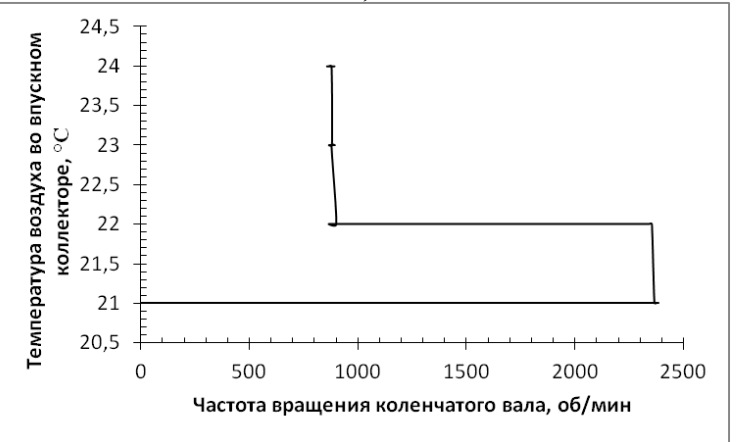

г)

Рисунок 2 - Обработка результатов измерения: а - зависимость изменения угла опережения зажигания для 1 цилиндра от частоты вращения коленчатого вала; б - зависимость изменения датчика положения дроссельной заслонки от частоты вращения коленчатого вала; в - зависимость изменения расхода воздуха, измеренного по ДМРВ от частоты вращения коленчатого вала; гзависимость изменения температуры воздуха во впускном коллекторе от частоты вращения коленчатого вала.

\section{Заключение}

Приведенные результаты компьютерной диагностики дают комплексную оценку состояния автомобиля для проведения технического обслуживания или ремонта. Все необходимые сведения о неисправностях автомобиля формируются в специальных клиентских отчетах, где указываются ошибки ЭБУ, паспорта автомобиля, ЭБУ, калибровки, таблицы коэффициентов топливоподачи и др.

\section{References:}

1. (2017) Electronic control unit. Available: https://en.wikipedia.org/wiki/Electronic_control _unit (Accessed: 07.02.2017).
2. (2017) Lada Granta. Available: https://ru.wikipedia.org/wiki/Lada_Granta (Accessed: 07.02.2017). 


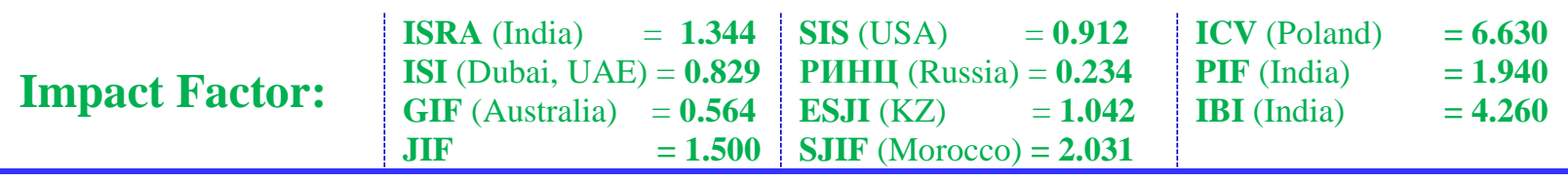

3. (2009) Diagnostics of cars electronic systems by devices SPE "NTS". Eleventh edition, supplemented. - Samara: SPE "NTS". - 183 p.

4. (2017) Motor-Tester MT10KM. Available: http://www.nppnts.com/index.php? $\bmod =\mathrm{mtmt} 1$ 0km (Accessed: 07.02.2017).

5. (2017) On-board diagnostics. Available: https://en.wikipedia.org/wiki/Onboard_diagnostics (Accessed: 07.02.2017).
6. (2017) OBD-II PIDs. Available: https://en.wikipedia.org/wiki/OBD-II_PIDs (Accessed: 07.02.2017).

7. (2017) Ignition advance. Available: https://ru.wikipedia.org/wiki/Опережение заж игания (Accessed: 07.02.2017).

8. (2017) Throttle position sensor. Available: https://en.wikipedia.org/wiki/Throttle_position sensor (Accessed: 07.02.2017). 